\title{
The AgNOR quantity as prognostic parameter in choroidal melanomas: a standardised analysis
}

\author{
G. Tuccari ${ }^{\text {a,* }}$, J.A. Giménez-Mas ${ }^{\text {c }}$, F. Fedele ${ }^{\text {a }}$, \\ C. Del-Agua ${ }^{c}$, B. Melcon ${ }^{d}$, C.J. Trombetta ${ }^{b}$ and \\ G. Giuffrè ${ }^{\mathrm{a}}$ \\ ${ }^{\text {a }}$ Department of Human Pathology, University of \\ Messina, Italy \\ ${ }^{\mathrm{b}}$ Institute of Ophthalmology, University of Messina, \\ Italy \\ ${ }^{\mathrm{c}}$ Institute of Pathology, Hospital Miguel Servet, \\ Zaragoza, Spain \\ ${ }^{\mathrm{d}}$ Institute of Ophthalmology, Hospital Miguel Servet, \\ Zaragoza, Spain
}

Received 10 August 1999

Accepted 10 February 2000

In order to assess the prognostic significance of silver-stained nucleolar organizer region (AgNOR) proteins, a standardised analysis has been performed on 34 ocular globes with choroidal melanomas. On formalin-fixed paraffin-embedded sections, the visualisation and quantification of AgNORs were achieved according to the guidelines of the Committee on AgNOR Quantification (1995); statistical analysis was performed on the mean AgNOR area values (NORA). We have encountered significantly higher NORA values in nonspindle shaped elements, in tumours of larger dimensions as well as in those with worse clinical course; no correlations were achieved when the AgNOR quantity was compared with age, sex and amount of pigment. The comparison of Kaplan-Meier survival curves revealed that patients affected by melanomas with higher NORA values $\left(>3.327 \mu \mathrm{m}^{2}\right)$, non-spindle cell histotype and increased size of tumour had a worse prognosis; finally, by Cox multivariate analysis, the AgNOR quantity appeared the only independent prognostic variable to predict the final outcome of patients.

Keywords: AgNORs, standardised AgNOR analysis, choroidal melanoma, proliferation, prognosis

\footnotetext{
${ }^{*}$ Correspondence to: Prof. Giovanni Tuccari, MD, Department of Human Pathology, Policlinico Universitario, Pad. D, 98100 Messina, Italy. Tel.: +39 090 2212539; Fax: +39 090 2938324; E-mail: tuccari@imeuniv.unime.it.
}

\section{Introduction}

Silver-stained nucleolar organizer region (AgNOR) proteins are a set of argyrophilic non-histone proteins localised in the nucleolar organizer region and associated with ribosomal genes [8,27]; moreover, the quantity of AgNOR proteins has been demonstrated to be strictly related to the rapidity of cell proliferation $[4,6$, 7,20].

The AgNOR technique has been extensively applied to human neoplasias, even if its diagnostic capability to discriminate between benign and malignant lesions is still controversial $[9,24]$; however, studies concerning the AgNOR applications in neoplastic pathology have stressed the prognostic value of this histochemical method [1,2,6,11-13,19,23-25,28].

In ophthalmic neoplastic pathology, the AgNOR method has been applied to assess the malignancy of conjunctival and uveal tumours [14,18,29]. In particular, an evident increase of mean AgNOR value has been reported in conjunctival squamous carcinomas in comparison with hyperplastic-dysplastic lesions [18], while malignant uveal and conjunctival melanomas showed higher mean AgNOR counts than benign nevi or primary acquired melanosis [14,29]; nevertheless, the intervening "grey" zone of overlap between AgNOR values in cases of benign and malignant ocular neoplasms limited the extensive application of AgNOR technique in diagnostic histopathology. Recently, conflicting papers have proposed the AgNOR technique as a tool to evaluate the prognosis of uveal melanomas $[3,30]$, although numerical and morphometric AgNOR parameters utilized were not comparable and standardised [3,30]; therefore, in the present study, we have utilised for the first time the standardised procedure proposed by the European Committee on AgNOR Quantification [22] in order to assess the prognostic value of nucleolar silver stained proteins in these tumours. 
Table 1

\begin{tabular}{lccc}
$\begin{array}{l}\text { Clinico-pathological data and corresponding mean NORA values }\left(\mu \mathrm{m}^{2}\right) \\
\text { in choroidal melanomas }\end{array}$ & & & \\
\hline Parameter & No. & NORA \pm SD & $P$ value \\
\hline Sex & 12 & $3.394 \pm 1.008$ & NS \\
$\quad$ Male & $22(18)^{*}$ & $3.283 \pm 0.983$ & \\
$\quad$ Female & & & $<0.001$ \\
Size of tumour & 8 & $2.473 \pm 0.447$ & \\
$\quad$ Small & $14(11)^{*}$ & $3.227 \pm 0.760$ & \\
$\quad$ Medium & $12(11)^{*}$ & $4.048 \pm 0.941$ & \\
$\quad$ Large & & & $<0.001$ \\
Histological group & $13(12)^{*}$ & $2.592 \pm 0.428$ & \\
$\quad$ Spindle cells type & $21(18)^{*}$ & $3.817 \pm 0.935$ & \\
$\quad$ Non-spindle cells type & & & NS \\
Amount of pigment & 8 & $3.428 \pm 1.091$ & \\
$\quad$ Absent & 16 & $3.227 \pm 0.965$ & \\
$\quad$ Moderate & $10(6)^{*}$ & $3.460 \pm 1.006$ & \\
$\quad$ Rich & & & $<0.001$ \\
Clinical course & $28(24)^{*}$ & $2.976 \pm 0.739$ & \\
Alive & 6 & $4.733 \pm 0.253$ & \\
$\quad$ Death of disease & 6
\end{tabular}

*In four cases of melanomas the excessive pigment or necrosis have made the morphometric assessment of AgNORs unreliable; NS $=$ not significant.

\section{Materials and methods}

Surgical samples of ocular globes from 34 patients (12 male, 22 female; mean age 57.5 years, ranging from 30 to 83 years) affected by choroidal melanomas were collected from files of our institutions and included in this study. The clinico-pathological data and characteristics of melanomas were determined according to criteria of McLean et al. [16,17] and summarised in Table 1; moreover, data concerning follow-up and cause of death were also available from city registry offices.

All surgical samples were fixed in $10 \%$ neutral formalin for 24-36 hrs at room temperature and then embedded in paraffin at $56^{\circ} \mathrm{C}$. From each tissue block, two consecutive $3 \mu \mathrm{m}$ thick sections were cut and mounted on silane-coated glasses, then dewaxed in xylene, rehydrated in graded ethanols. The Haematoxylin-Eosin (H\&E) stain allowed to made the following histopathological diagnosis: spindle cell type melanoma (13), epithelioid melanoma (7), mixed cell type melanoma (13) necrotic melanoma (1); all the cases were then grouped in spindle cell type (13) and non-spindle cell type (21).

The AgNOR technique was performed according to guidelines of the Committee on AgNOR Quantifica- tion [22]; in particular, the second section was immersed in sodium citrate buffer $(\mathrm{pH} \mathrm{6})$ and incubated in wet autoclave at $120^{\circ} \mathrm{C}(1.1-1.2 \mathrm{bar}$, at sea level) for $20 \mathrm{~min}$ and then allowed to cool down to $37^{\circ} \mathrm{C}$. Successively, slides were immersed in a freshly prepared silver-staining solution containing one part of volume of $2 \%$ gelatine in $1 \%$ formic acid and two parts of $25 \%$ aqueous silver nitrate solution, at $37^{\circ} \mathrm{C}$ in a thermostatically controlled environment for $11 \mathrm{~min}$; the reaction was then stopped by washing the slides with bidistilled deionized water in order to remove unwanted silver precipitates. Finally, all sections were dehydrated in ascending ethanols, clarified in xylene and mounted with a synthetic medium (Permount).

The quantification of AgNORs was performed by an image analysis system (Immagini e Computer, RhoMilan, Italy) consisting of an optical Leitz microscope fitted with a single chip colour CCD video camera (Ikegami ICD-840PDC, Ikegami Tsushinki Co. Ltd., Tokyo, Japan) with a resolution of $460 \times 420$ (horizontal $\times$ vertical) TV lines, a colour monitor and an image processing unit installed in a $486 / 33 \mathrm{MHz}$ processorbased personal computer. For each slide examined, microscopic fields representative of the lesions were assessed excluding, on the basis of the corresponding H\&E stained section, areas in which regressive changes, frank necrosis, excess of melanic pigment as 


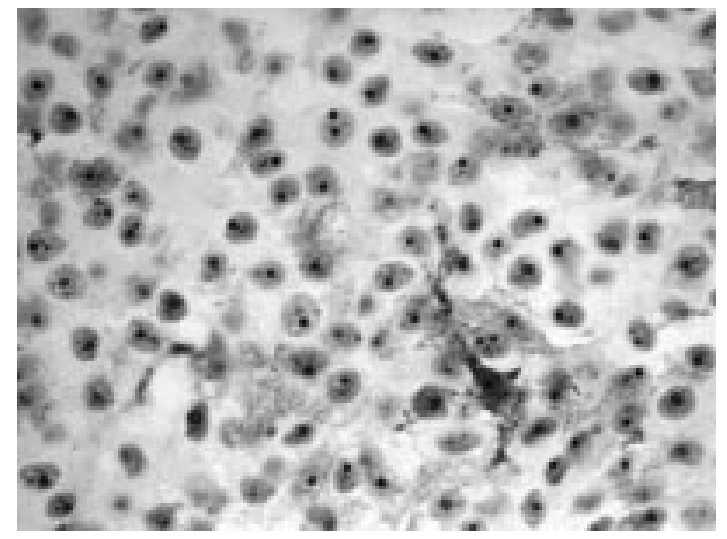

(a)

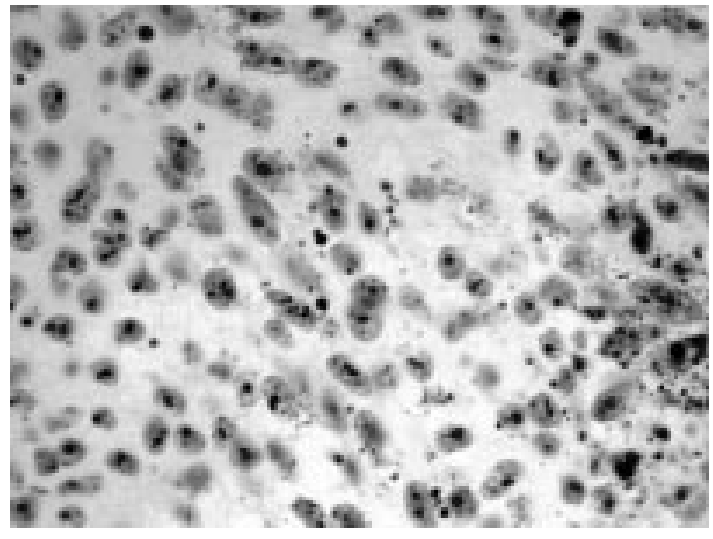

(b)

Fig. 1. Choroidal melanoma. (a) AgNORs clustered in regularly shaped collections, $\times 157$. (b) Black intranuclear dots in a pigmented area, $\times 157$.

well as technical artefacts were present. For this reason, four cases were considered not suitable for the morphometric assessment of AgNORs since the pigment obscured specific silver precipitates or the tumour mass was wholly necrotic, similarly to that elsewhere suggested [14]. The mean area $\left(\mu \mathrm{m}^{2}\right)$ of AgNORs per cell (NORA) was evaluated at one focal plane with a $\times 40$ objective lens in at least 100 nuclei per specimens (mean 150); specific softwares, IM 5200 (Microscience Inc.) and AgNOR (Immagini e Computer, Rho-Milan, Italy), were utilised to determine mean NORA values per cell and per case, respectively.

After testing the normal distribution of NORA values in all patients by Kolmogorov-Smirnov test, a cutoff point was determined utilizing the mean NORA value. A statistical descriptive analysis was performed for each clinico-pathological parameter; differences among categories were assessed by Analysis of variance and the Newman-Keuls' test, while correlations between continuous parameters were investigated by Spearman's rank test. Survival analysis was performed by the Kaplan-Meier method and for the comparison of the survival curves, the Mantel-Cox log-rank test was used. Finally, a multivariate analysis (Cox regression model) was utilized to determine the independent effect of each variable on survival. A $P$ value less than 0.05 was considered statistically significant.

\section{Results}

All cases of melanoma showed an adequate silver staining intensity, homogeneously present throughout the whole section, with a variable amount of melanic pigment (Fig. 1(a,b)). The AgNORs precipitates showed an intranuclear localisation with a round shape (Fig. 1a), although this pattern was sometimes less regular with a scattered distribution (Fig. 1b); moreover, the AgNORs were clearly distinguishable as black dots also within nucleoli (Fig. 1(a,b)).

In choroidal melanoma specimens, NORA values of neoplastic elements exhibited a normal distribution (2tailed $P=0.381$ ) with a mean of $3.327 \pm 0.977 \mu \mathrm{m}^{2}$; NORA values relative to clinico-pathological data are given in Table 1. A significant $P$ value was achieved in the correlation of NORA with size of tumour, histological group and clinical course, while no relationships were found in comparison to sex and amount of pigment (Table 1); moreover, the AgNOR quantity in melanomas was unrelated to the patient's age. The follow-up time of patients ranged from 4 to 180 months (median 41). Six patients dead of disease with metastatic localisations (3 liver, 2 liver and brain, 1 liver and adrenal glands), while 28 were well and alive; no relationship between mean NORA values in the hepatic versus non-hepatic site of metastases was found. Data obtained by univariate analysis of clinico-pathological and NORA parameters concerning cancer-specific mortality are reported in Table 2; moreover, utilizing the mean NORA value encountered in melanomas as a cut-off point, 12/30 cases had greater NORA values than $3.327 \mu \mathrm{m}^{2}$. Among examined parameters, size of tumour, histological group and NORA showed significant $P$ values; the survival curves of patients with low and high NORA values are illustrated in Fig. 2. Finally, by Cox multivariate analysis, the NORA value emerged as the exclusive independent prognostic variable (Table 3). 


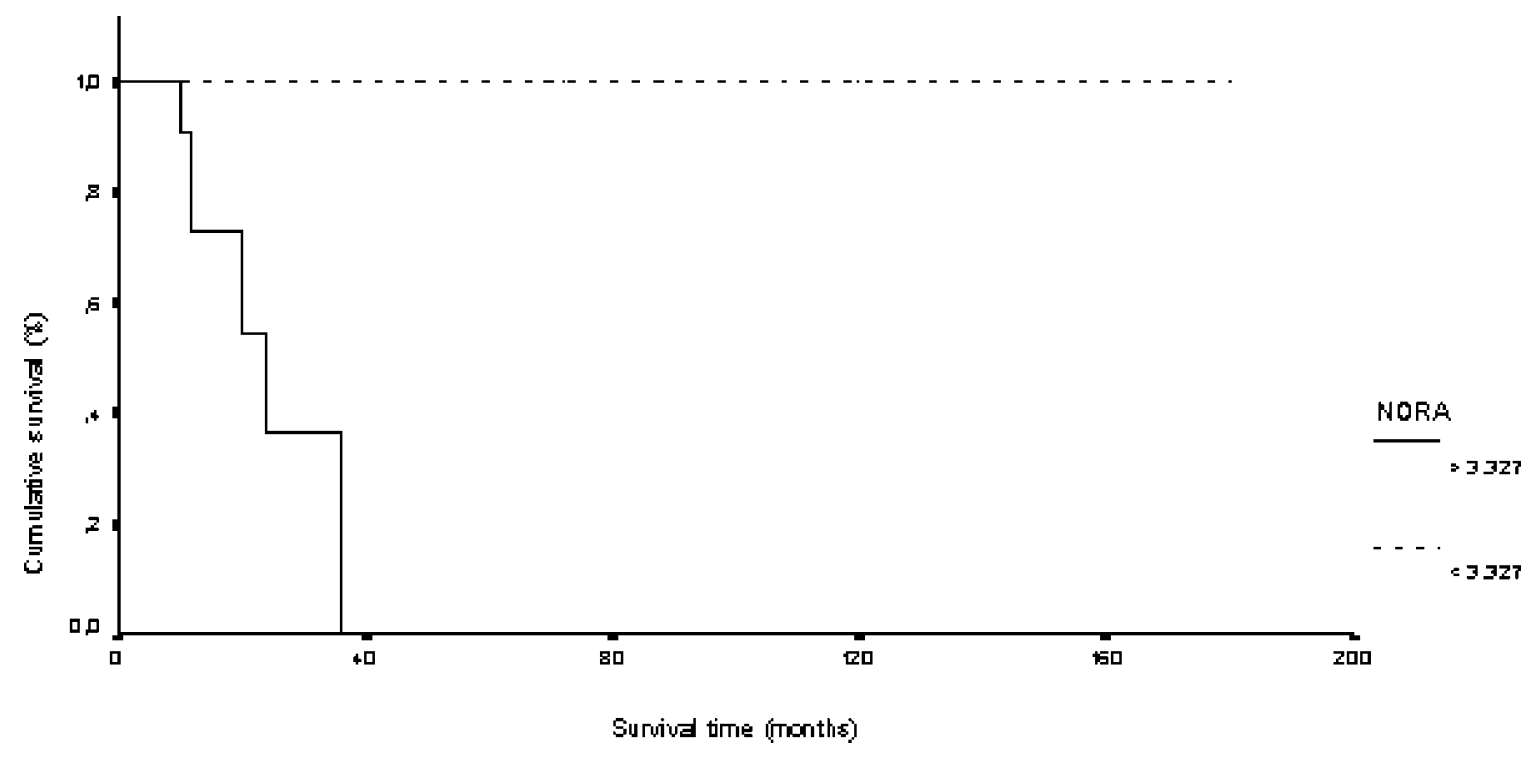

Fig. 2. Kaplan-Meier survival curves of patients with low and high NORA values.

Table 2

Prognostic parameters examined in choroidal melanomas: a univariate analysis to cancer-specific mortality by Mantel-Cox log-rank test

\begin{tabular}{lrcc}
\hline Parameter & $\chi^{2}$ & DF & $P$ value \\
\hline All patients $(n=34)$ & & & \\
Sex & 0.82 & 1 & NS \\
Size of tumour & 11.09 & 2 & $<0.0039$ \\
Histological group & 7.25 & 1 & $<0.0071$ \\
Amount of pigment & 0.51 & 2 & NS \\
NORA $(n=30)^{*}$ & 17.42 & 1 & $<0.0001$ \\
\hline
\end{tabular}

$\mathrm{NS}=$ not significant; DF $=$ degrees of freedom; $*$ in four cases of melanomas the excessive pigment or necrosis have made the morphometric assessment of AgNORs unreliable.

Table 3

Multivariate survival analysis by Cox regression model in 30 cases of choroidal melanomas

\begin{tabular}{lcccc}
\hline Variable & $\beta$ & $\operatorname{SE}$ & $\operatorname{Exp}(\beta)$ & $P$ value \\
\hline NORA & 2.051 & 0.806 & 7.778 & $<0.01$ \\
\hline
\end{tabular}

$\beta=$ regression coefficient; $\mathrm{SE}=$ standard error; $\operatorname{Exp}(\beta)=$ ratio of risk.

In Table 4 are summarized papers concerning the status about AgNOR analysis in uveal melanomas, including methodological and pathological data as well as survival analysis.

\section{Discussion}

Malignant melanoma develops more frequently in the uveal tract of the eye than in any other site of the body except the skin $[5,16]$; it represents the most common intraocular neoplasm and its incidence is oneeighth that of cutaneous melanoma $[5,16]$. It has been suggested that many factors may influence the survival of patients affected by uveal melanomas and may predict the appearance of distant metastases [16,31]; in particular, cell type, largest tumour dimension, scleral extension and mitotic activity, in combination, have been reported as the best prognostic indicators [14,15]. Nevertheless, the best objective method for estimating the malignant potential of uveal melanomas has been considered the computerised cytomorphometric evaluation of nucleolar area, when combined with measurement of largest tumour diameter [10]. In previous studies concerning conjunctival and uveal melanomas, the proliferation rate has been assessed by the silver staining of the nucleolar organizer regions [14,29]; nevertheless in these studies, by a not standardised and time consuming procedure, AgNORs have been counted in one-hundred cells per specimen, while no informations about the area of argyrophilic nucleolar organizer regions have been furnished [3,14,29]. More recently, two papers coming from the same south area of Italy have been performed on uveal melanomas, utilizing a different manner of AgNOR determination as well as different morphometric parameters and reaching dissonant conclusions $[3,30]$. In detail, the multivariate analysis didn't provide any additional information about prognosis, although patients having a high AgNOR count had a worse survival [3]; on the other hand, patients with the highest values of AgNOR mean area 
Table 4

Summary of studies about AgNOR analysis in uveal melanoma

\begin{tabular}{lllll}
\hline Authors & $\begin{array}{l}\text { Marcus et al. } \\
(1990)\end{array}$ & $\begin{array}{l}\text { Baldi et al. } \\
(1998)\end{array}$ & $\begin{array}{l}\text { Staibano et al. } \\
(1998)\end{array}$ & Present paper \\
\hline $\begin{array}{l}\text { Standardization } \\
\text { of the AgNOR } \\
\text { method }\end{array}$ & No & No & Yes \\
$\begin{array}{l}\text { Methodology } \\
\text { of quantitation }\end{array}$ & Counting & Counting & Image analysis & Image analysis \\
$\begin{array}{l}\text { Relation to } \\
\text { pathological data }\end{array}$ & Yes & (histotype, size of tumour) & (histotype, size of tumour) & (histotype, size of tumour) (histotype, size of tumour) \\
Relation to the clinical course & Yes & Yes* & Yes & Yes \\
\hline
\end{tabular}

*Only by univariate analysis.

showed poorer clinical behaviour, even if no correlation was found between AgNORs and largest tumour dimensions [30]. Therefore, on the light of these reports, we have considered the contribute of the AgNOR technique remains to be definitively determined in order to provide additional prognostic informations in this field of ocular pathology. To achieve good and reproducible results, we have utilised the standardised AgNOR technique [22] to assess the AgNOR quantity in choroidal melanomas, measuring the area of silver stained precipitates by morphometric analysis; in particular, by wet-autoclave pre-treatment, we have obtained a constantly high staining quality of singleinterphase AgNORs, independently of duration of formalin fixation and archival storage, similarly to that elsewhere reported $[21,26]$. Moreover, to ensure better comparisons between different laboratories, we have performed AgNOR staining at $37^{\circ} \mathrm{C}$ in a thermostatically controlled environment; finally, the quantification by an image analyser system is a further contribution to standardisation, being more objective and free of observer bias than counting AgNORs by eye.

In our cases of choroidal melanomas, no significant correlations were achieved when the AgNOR quantity was compared with age, sex and amount of pigment; nevertheless, significantly higher NORA amounts have been encountered in non-spindle cell type melanomas as well as in tumours of larger dimensions, similarly to that elsewhere reported [30]. However, in a previous study [14], mixed-cell melanomas have been found to have slightly higher AgNOR counts than spindle-cell melanomas, but this has been considered to be clinically unimportant; moreover, no relationships have been found between higher mean AgNOR scores and percentage of epithelioid cells per tumour as well as age, while a correlation of silver stained nu- cleolar organizer regions with tumour size has been disclosed [14]. Results of our univariate analysis to cancer-specific mortality in choroidal melanomas indicate the size of tumour and the cytological picture are morphologic prognostic parameters, as previously reported in literature $[10,12]$; in addition, when the mean AgNORs value has been utilised as a cut-off point, two groups of patients with different final outcome were selected, showing that patients with higher NORA values had a worse prognosis with an increased risk to die. Furthermore, the multivariate analysis by Cox regression model clearly documented that only NORA was an independent variable in choroidal melanomas; we suggest the AgNOR analysis may have a high rank order of influence on final outcome by the identification of patients at different risk of death, even if our data have still to be confirmed by larger series and by other groups. However, we retain that a standardized AgNOR technique may be largely applied in different histopathological laboratories, since its simplicity and reproducibility are useful in the assessment of followup surveillance.

\section{References}

[1] L. Antonangelo, F. Bernardi, V.L. Capelozzi, T.Y. Takagaki, R.N. Younes, N. Yagi and P.H. Saldiva, Morphometric evaluation of argyrophilic nucleolar organizer region is useful in predicting long-term survival in squamous cell carcinoma of the lung, Chest 111 (1997), 110-114.

[2] M. Aubele, G. Auer, U. Jutting, U. Falkmer and P. Gais, Prognostic value of quantitatively measured AgNORs in ductal mammary carcinoma, Analyt. Quant. Cytol. Histol. 16 (1994), 211-218.

[3] G. Baldi, F. Baldi, M. Maguire and M. Massaro-Giordano, Prognostic factors for survival after enucleation for choroidal melanoma, Int. J. Oncol. 13 (1998), 1185-1189. 
[4] E. Carbajo-Pérez, V. Alberca, V. Vicent-Villardon, T. Flores and S. Carbajo, Expression of argyrophilic nucleolar organizer regions (AgNORs) can be used to assess cellular proliferation as shown in rat thymic sections, Histochem. J. 25 (1993), 548553.

[5] S.J. Cutler and J.L. Young, Third national cancer survey: incidence data, in: National Cancer Institute Monograph, Vol. 41, US National Cancer Institute, Bethesda, MD, 1975.

[6] M. Derenzini, A. Pession, F. Farabegoli, D. Trerè, M. Badiali and P. Dehan, Relationship between interphasic nucleolar organizer regions and growth rate in two neuroblastoma cell lines, Am. J. Pathol. 134 (1989), 925-932.

[7] M. Derenzini, A. Pession and D. Trerè, Quantity of nucleolar silver-stained proteins is related to proliferating activity in cancer cells, Lab. Invest. 63 (1990), 137-140.

[8] M. Derenzini and D. Ploton, Interphase nucleolar organizer regions in cancer cells, Int. Rev. Exp. Pathol. 32 (1991), 149-192.

[9] M. Derenzini and D. Trerè, Importance of interphase nucleolar organizer regions in tumor pathology, Virchows Arch. B Cell. Pathol. 61 (1991), 1-8.

[10] J.W. Gamel, R.A. Greenberg, I.W. McLean, J.M. Seddon, D.M. Albert, R.E. Naids, R. Folberg and L.A. Donoso, A clinically useful method for combining gross and microscopic measurements to select high-risk patients after enucleation for cilio-choroidal melanoma, Cancer 57 (1986), 1341-1344.

[11] J.A. Giménez-Mas, M.P. Gallego-Calvo, M.P. Sanz-Moncasi, M.J. Rios-Mitchell, M.I. Vallero, M. Sanz-Anquela, J. Burriel and A. Bavai, AgNOR evaluation by image processing methods. Staining modifications and results in 126 invasive ductal breast carcinomas, Analyt. Quant. Cytol. Histol. 18 (1996), 918.

[12] G. Giuffrè, G. Barresi, G. Speciale, R. Sarnelli, M.A. Gioffrè Florio and G. Tuccari, Differences in AgNOR quantity between colorectal cancer and corresponding metastases: are they useful for prognostic purposes?, Eur. J. Histochem. 41 (1997), 111118.

[13] G. Giuffrè, R.A. Caruso, G. Barresi and G. Tuccari, Prognostic significance of standardized AgNOR analysis in early and advanced gastric carcinomas, Virchows Arch. 433 (1998), 261266.

[14] D.M. Marcus, J.B. Minkovitz, S.D. Wardwell and D.M. Albert, The value of nucleolar organizer regions in uveal melanoma, Am. J. Ophthalmol. 110 (1990), 527-534.

[15] I.W. McLean, W.D. Foster and L.E. Zimmerman, Prognostic factors in small malignant melanomas of choroid and ciliary body, Arch. Ophthalmol. 95 (1977), 48-58.

[16] I.W. McLean, W.D. Foster and L.E. Zimmerman, Uveal melanoma: location, size, cell type, and enucleation as risk factors in metastasis, Hum. Pathol. 13 (1982), 123-132.

[17] I.W. McLean, W.D. Foster, L.E. Zimmerman and J.W. Gamel, Modifications of Callender's classification of uveal melanoma at the Armed Forces Institute of Pathology, Am. J. Ophthalmol. 96 (1983), 502-509.

[18] M. Muscarà, G. Giuffrè, C.J. Trombetta, F. Bisantis and G. Tuccari, Nucleolar organizer regions (NORs) in dysplastic and neoplastic epithelial lesions of the conjunctiva, Pathologica $\mathbf{8 3}$ (1991), 281-288.
[19] M. Muscarà, G. Giuffrè, R. Rossiello, R. Sarnelli, G. Barresi and G. Tuccari, Gallbladder carcinoma: a video image analysis of AgNOR distribution and its relation to tumour stage and grade, Path. Res. Pract. 192 (1996), 407-413.

[20] D. Öfner, A. Hittmair, C. Marth, C. Öfner, M. Tötsch and G. Daxenbichler, Relationship between quantity of silver stained nucleolar organizer region associated proteins (AgNORs) and population doubling time in ten breast cancer cell lines, Path. Res. Pract. 188 (1992), 742-746.

[21] D. Öfner, A. Bankfalvi, K. Riehemann, B. Bier, W. Böcker and K.W. Schmid, Wet autoclave pretreatment improves the visualization of silver-stained nucleolar organizer-region-associated proteins in routinely formalin-fixed and paraffin-embedded tissues, Mod. Pathol. 7 (1994), 946-950.

[22] D. Öfner, M. Aubele, S. Biesterfeld, M. Derenzini, J.A. Gimenez-Mas, P. Hufnagl, D. Ploton, D. Trerè and J. Rüschoff, Guidelines of AgNOR quantification - first update, in: Cell Proliferation Assessment in Oncology, F. Hofstadter, R. Knuchel and J. Rüschoff, eds, Virchows Arch. 427 (1995), 341.

[23] D. Öfner, B. Riedmann, H. Maier, A. Hittmair, A. Rumer, M. Tötsch, B. Spechtenhauser, W. Böcker and K.W. Schmid, Standardized staining and analysis of argyrophilic nucleolar organizer region associated proteins (AgNORs) in radically resected colorectal adenocarcinoma - correlation with tumour stage and long-term survival, J. Pathol. 175 (1995), 441-448.

[24] D. Öfner and K.W. Schmid, Clinical significance of nucleolar organizer region associated proteins in tumour pathology, in: Cell Proliferation Assessment in Oncology, F. Hofstadter, R. Knuchel and J. Rüschoff, eds, Virchows Arch. 427 (1995), 340

[25] D. Öfner, B. Bier, S. Heinrichs, M. Berghorn, M. Dünser, H.A. Hagemann, D. Langer, W. Böcker and K.W. Schmid, Demonstration of silver-stained nucleolar organizer region associated proteins (AgNORs) after wet autoclave pretreatment in breast carcinoma - correlation to tumour stage and long-term survival, Breast Cancer Res. Treat. 39 (1996), 165-176.

[26] D. Öfner and K.W. Schmid, Standardized AgNOR analysis: its usefulness in surgical oncology, Histochem. Cell. Biol. 106 (1996), 193-196.

[27] D. Ploton, M. Menager, P. Jeannesson, G. Himber, F. Pigeon and J.J. Adnet, Improvement in the staining and in the visualization of the argyrophilic proteins of the nucleolar organizer region at the optical level, Histochem. J. 18 (1986), 5-14.

[28] J. Rüschoff, A. Bittinger, K. Neumann and P. SchmitzMoormann, Prognostic significance of nucleolar organizing regions (NORs) in carcinomas of the sigmoid colon and rectum, Path. Res. Pract. 186 (1990), 85-91.

[29] M.A. Saornil, D.M. Marcus, D. Doepner, G. Apolone, V. Torre and D.M. Albert, Nucleolar organizer regions in determining malignancy of pigmented conjunctival lesions, Am. J. Ophthalmol. 115 (1993), 800-805.

[30] S. Staibano, P. Orabona, E. Mezza, G. Salvatore, F. Tranfa, D. Capone, M.E. Errico, G. Bonavolontà, A. Lucariello and G. De Rosa, Morphometric analysis of AgNORs in uveal malignant melanoma, Analyt. Quant. Cytol. Histol. 20 (1998), 483-492.

[31] L.E. Zimmerman and I.W. McLean, An evaluation of enucleation in the management of uveal melanomas, Am. J. Ophthalmol. 87 (1979), 741-760. 


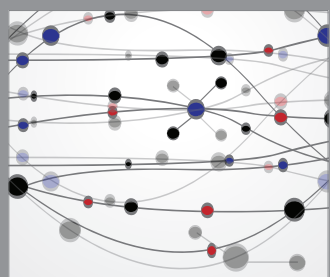

The Scientific World Journal
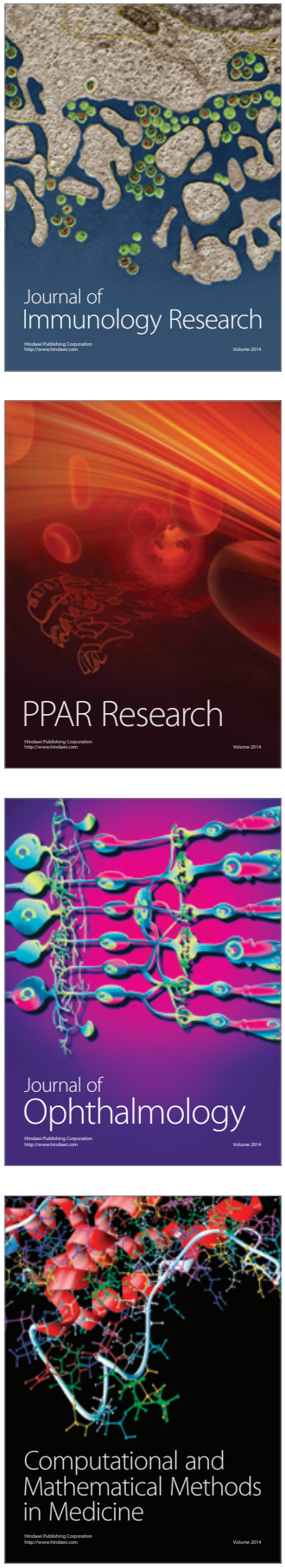

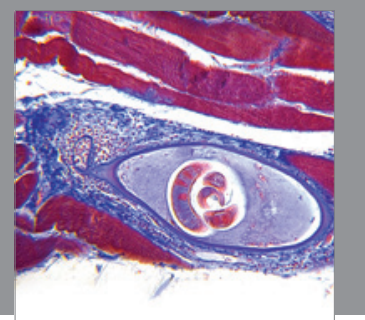

Gastroenterology

Research and Practice
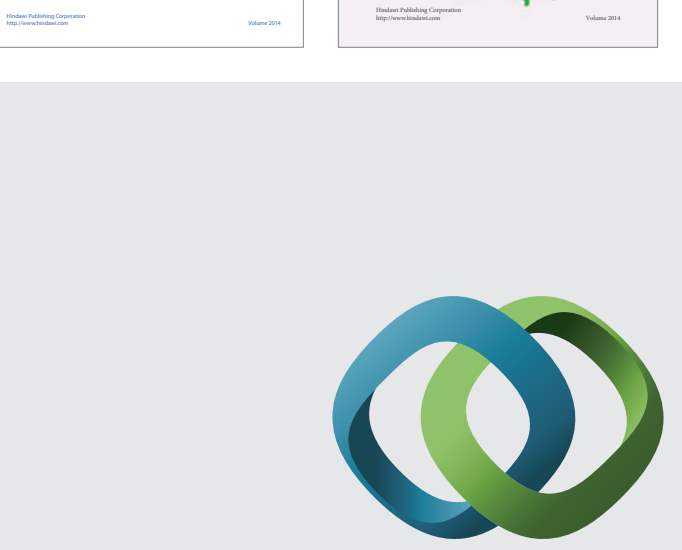

\section{Hindawi}

Submit your manuscripts at

http://www.hindawi.com
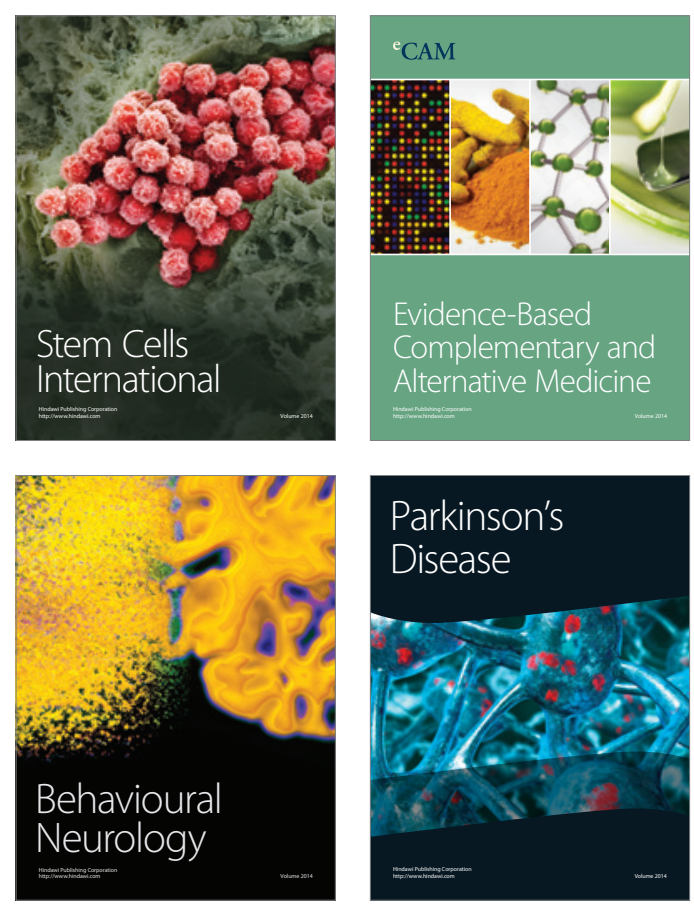

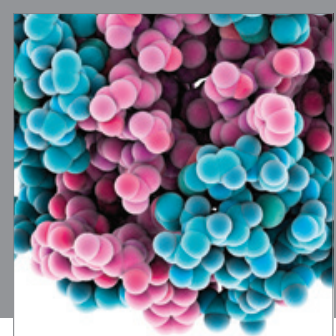

Journal of
Diabetes Research

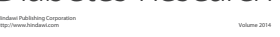

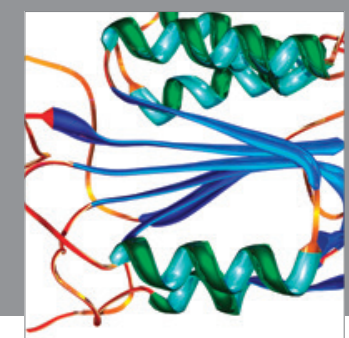

Disease Markers
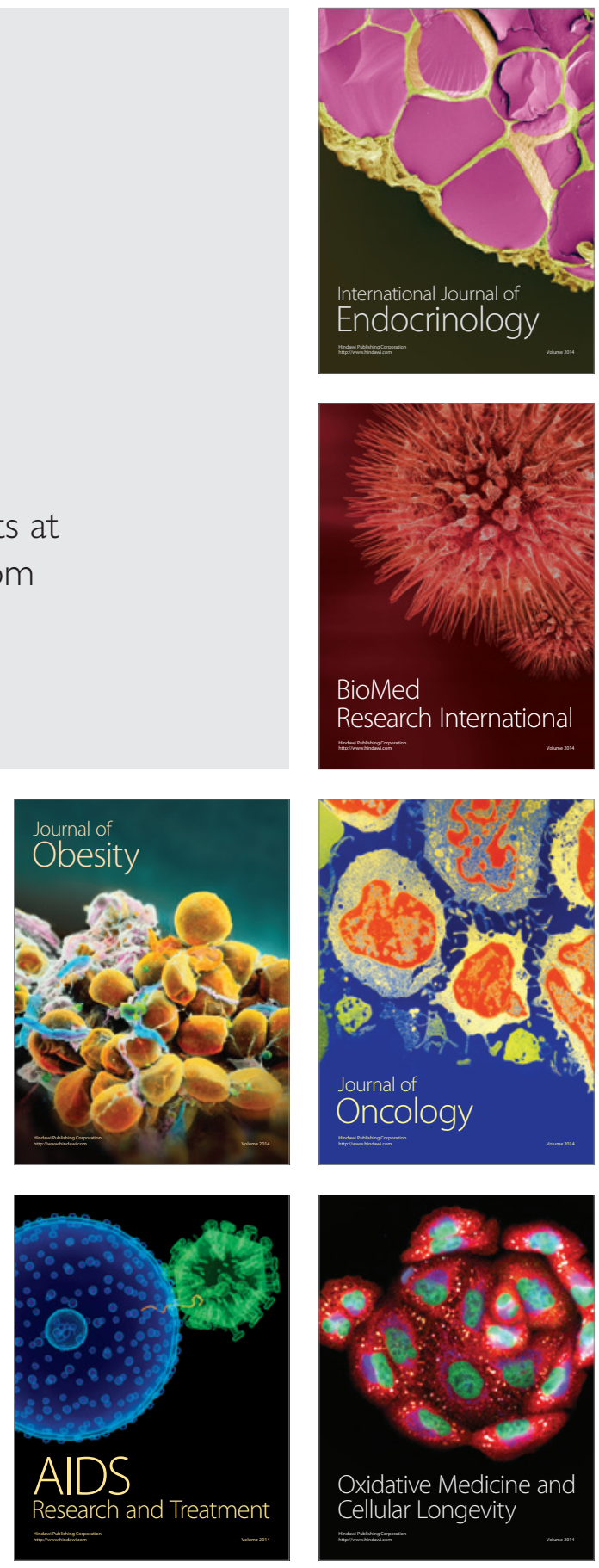